\title{
High-school Students' Beliefs about Learning English and Arabic
}

\author{
Maryam Meshkat \\ Faculty of Humanities, Shahid Rajaee University, Tehran, Iran \\ E-mail address: maryammeshkat@yahoo.com \\ Fateme Saeb (Corresponding author) \\ English Department, Faculty of Humanities, Shahid Rajaee University, Tehran, Iran \\ E-mail address: f.saeb1384@gmail.com
}

Received: 03-01-2013

doi:10.7575/aiac.ijalel.v.3n.3p.211
Accepted: 13-02-2014

Published: 01-05-2014

\begin{abstract}
This paper reports on a comparative study exploring Iranian high-school students' beliefs about learning English and Arabic. Horwitz's (1987) Beliefs about Language Learning Inventory (BALLI) was used to collect data from 540 highschool students. One-way multivariate analysis of variance was conducted to analyze the data. The MANOVA results revealed significant differences $(F(5,533)=47.72, P=.000)$ between students' beliefs about learning English and Arabic in four categories of the BALLI: foreign language aptitude, the nature of language learning, learning and communication strategies, and motivation and expectations. Students' beliefs about the difficulty of learning English and Arabic were not significantly different. The findings might be influential in developing and designing more effective language teaching programs in high-school context.
\end{abstract}

Keywords: Foreign language learning, Beliefs about language learning, BALLI, High-school students, Arabic

\section{Introduction}

Since the mid-1980s, an increasing interest in the role of individual learners' in language learning led researchers to explore learner variables as a method of analyzing diversities in students' command in learning a foreign or second language. Learners' beliefs about language learning are among these variables which have been explored and investigated as heated topics in the realm of second language acquisition.

Language learning beliefs have been defined as "general assumptions that students hold about themselves as learners, about factors influencing language learning, and about the nature of language learning and teaching" (Victori \& Lockhart, 1995, p. 224). Barcelos (2000) argued that belief is a way of perceiving the world that generates confidence to act upon matters accepted as true, but which may be questioned in the future. Beliefs in such a contextual approach are dynamic, socially constructed, situated, paradoxical and related to action. Learning beliefs tend to shape students' perceptions as well as influencing what students do in the classroom. He suggested that teachers should understand beliefs as resources the students use to make sense of their context and to deal with it. Horwitz (1999) also deemed it critical to be conscious about learner beliefs in order to better appreciate their approaches to language learning, and their practice of learning strategies to improve language education.

So far, belief studies have been mostly concentrated on English language learners' beliefs using The Beliefs about Language Learning Inventory (BALLI), developed by Horwitz (1987) as the instrument in different ESL and EFL contexts. These studies have investigated the link between beliefs and language learning strategies (Park, 1995; Wenden, 1986; Yang, 1999) gender (Bernat \& Lloyd, 2007; Tercanlioglu, 2005), language proficiency (Abedini et al., 2011), foreign language anxiety (Oh, 1996; Truitt, 1995; Young, 1991), the effect of culture on beliefs (Horwitz, 1999), and the latent aspects of language learners' beliefs (Sakui \& Gaines, 1999).

A few belief studies (Altan, 2006; Diab, 2006; Rieger, 2009) have compared and contrasted language learning beliefs of different target language groups. Altan (2006) investigated the language learning beliefs of English, German, French, Japanese and Arabic language learners. In spite of slightly different percentages of responses to the BALLI, the overall pattern of responses was strikingly consistent across the five language groups. Rieger (2009), however, found statistically significant differences between German and English language learners' beliefs in relation to two BALLI factors: the difficulty of language learning and the nature of language learning. Diab's (2006) study is unique in that it compared the beliefs of the same learners about learning two different foreign languages, namely, English and French. She, too, found statistically significant differences in beliefs about the difficulty of language learning and motivation for learning English and French.

To date, most of belief studies in Iran have focused on the relationship between the learners' beliefs and learning strategy use or language proficiency (Abedini et al., 2011; Dehghan Harati, 2011; Ghabanchi and Meidani, 2012; 
Ghavamnia et al., 2011; Khodadadi, 2009; Yamini and Dehghan, 2005; Zare-ee, 2010). These studies have been done almost exclusively with students at tertiary levels. No study has yet compared Iranian high-school students' beliefs about learning English and Arabic as the two foreign languages taught at public high schools. Therefore, as a first research attempt in this area, the present study was conducted to answer this question: Is there any significant difference between Iranian high-school students' beliefs about learning English and Arabic?

\section{Foreign language education in Iran}

English and Arabic are introduced simultaneously into the educational curriculum at the first grade in Iranian junior high schools and the students continue studying them up to the fourth grade in senior high school. These are compulsory subjects and the classes are held for at least two hours a week. English, however, is followed at the tertiary level and is a compulsory subject for at least four credits for all majors in all universities nationwide, whereas studying Arabic is restricted to the high school except for those who choose to study Arabic as their major at the university. Therefore, English enjoys a more powerful status as a foreign language in Iran. This superiority is also explained by the availability of English institutes outside of school which plays a considerable role in improving English language teaching and learning, while there are no such institutes for learning Arabic.

Yet, the religious importance of Arabic language must be taken into account since it is the language of the Holy Qur'an and many other Islamic source books and materials which are involved in daily prayers and other religious rituals and activities of most Iranians. Many Iranian children learn a few Arabic sentences (from the Holy Qur'an) even before they start school. Also, thousands of Arabic words have entered the Persian language through deep historical, cultural and religious ties with this language, since Arabic has been the language of science, scholarship, philosophy and even literature for several centuries after the arrival of Islam into Iran in $644 \mathrm{AD}$.

Nonetheless, regarding the popularity of these two foreign languages, English surpasses Arabic. This might be because young people are getting continuously familiar with some attractive aspects of western cultures represented by the English language through movies, satellites, T.V, the Internet, etc. Also, possessing a full command of English contributes to better job opportunities and even a higher social prestige. These are factors that might have influenced students' beliefs about learning these two languages and thus are taken into account in surveys like the present study.

\section{Method}

\subsection{Participants}

Five hundred and forty high-school students from different cities in Iran participated in this study. All of them were female. Their age ranged from 14 to 18 years. The sample included students of all four grades in high school and the three majors of humanities, sciences and mathematics. All students had studied English for at least three years at junior high-school and they were at a lower intermediate level of proficiency.

\subsection{Instrumentation}

The instruments in this study were two modified versions of the Beliefs about Language Learning Inventory (BALLI, ESL/EFL version) developed by Horwitz (1987). The BALLI assesses learners' beliefs within five categories: the difficulty of language learning, foreign language aptitude, the nature of language learning, learning and communication strategies, and motivation and expectations. Items are scored on a five-point Likert scale: $1=$ strongly disagree, $2=$ disagree, $3=$ neither agree nor disagree, $4=$ agree, $5=$ strongly agree. The inventory was translated into Persian by the researcher. A few questions regarding demographic information were also added to the questionnaire. One questionnaire involved items concerning students' beliefs about learning English, and the other assessed students' beliefs about learning Arabic. The two questionnaires contained exactly the same sentences except for the words "English" and "Arabic". Cronbach alpha reliability for the translated version was found to be .74 for English and .66 for Arabic.

\subsection{Data collection and analysis}

The questionnaires were administered during the students' regular class time by their English and Arabic teachers. For each target language, 270 copies were distributed. Before the administration procedure, a brief explanation on the purpose of the study was given to the students. The gathered data were analyzed using SPSS. Descriptive statistics, including frequencies, means, and standard deviations, were computed. To find out the significance of the difference between beliefs about learning English and Arabic, a one-way between groups multivariate analysis of variance was conducted.

\section{Results}

To examine whether the target language has any effect on the students' beliefs about language learning, the data were submitted to a one-way multivariate analysis of variance (MANOVA). The five belief factors and the target language were used as the dependent and the independent variables respectively. The MANOVA results revealed a statistically significant difference between the students' beliefs about learning English and Arabic, $F(5,533)=47.72, P=.000$; Wilks' Lambda $=.69$; partial eta squared $=.31$. The results for each of the five belief factors were also obtained separately (Table 1). 
Table 1. One-way MANOVA for the effect of target language on the five belief factors

\begin{tabular}{lcccccc}
\hline Dependent Variable & $\begin{array}{c}\text { Type III Sum of } \\
\text { Squares }\end{array}$ & df & Mean Square & F & Sig. & $\begin{array}{c}\text { Partial Eta } \\
\text { Squared }\end{array}$ \\
\hline Aptitude & 109.773 & 1 & 109.773 & 7.160 & .008 & .013 \\
Difficulty & 22.718 & 1 & 22.718 & 4.637 & .032 & .009 \\
Nature & 2224.582 & 1 & 2224.582 & 210.674 & .000 & .282 \\
Strategy & 140.509 & 1 & 140.509 & 12.886 & .000 & .023 \\
Motivation & 1065.724 & 1 & 1065.724 & 36.828 & .000 & .064 \\
\hline
\end{tabular}

As seen in Table 1, the difference of four belief factors including foreign language aptitude, the nature of language learning, learning and communication strategies, and motivation and expectations reached statistical significance, using a Bonferroni adjusted alpha level of .01. The only factor which was not significantly different between the two target languages was beliefs about the difficulty of language learning. An examination of mean scores of the two groups in the five belief factors (Table 2) revealed higher means for beliefs about learning English compared to Arabic in the four belief factors which turned out to be statistically significant.

Table 2. Mean scores of English and Arabic learning beliefs in the five belief factors

\begin{tabular}{lllrrr}
\hline Dependent Variable & language & & & \multicolumn{2}{c}{$95 \%$ Confidence Interval } \\
\cline { 5 - 6 } & & Mean & Std. Error & Lower Bound & Upper Bound \\
\hline Aptitude & English & 31.695 & .239 & 31.226 & 32.164 \\
& Arabic & 30.793 & .238 & 30.324 & 31.261 \\
\hline Difficulty & English & 13.862 & .135 & 13.597 & 14.128 \\
& Arabic & 13.452 & .135 & 13.187 & 13.716 \\
\hline Nature & English & 26.045 & .198 & 25.655 & 26.434 \\
& Arabic & 21.981 & .198 & 21.593 & 22.370 \\
\hline Strategy & English & 26.710 & .201 & 26.315 & 27.106 \\
& Arabic & 25.689 & .201 & 25.294 & 26.084 \\
\hline Motivation & English & 20.316 & .328 & 19.672 & 20.960 \\
& Arabic & 17.504 & .327 & 16.861 & 18.147 \\
\hline
\end{tabular}

\section{Discussion}

The data analysis revealed a number of significant findings. MANOVA results showed that the students held significantly different beliefs about learning English and Arabic in four belief factors of foreign language aptitude, the nature of language learning, learning and communication strategies, and motivation and expectations. This result is contrary to the findings of Altan (2006) who found no significant differences in the beliefs of learners of diverse target languages. Also, this study found that there was no significant difference in students' beliefs about the difficulty of learning English and Arabic. This is inconsistent with the findings of Diab (2006) and Rieger (2009) who found significant differences in students' beliefs about the difficulty of learning English and German, and English and French. This means that Iranian students evaluate learning English and Arabic as being of the same level of difficulty. On the whole, these findings are particularly interesting since they show that learners of different target languages share a common belief in the concept of a language learning difficulty hierarchy. The difference of the students' beliefs in the four belief factors of foreign language aptitude, the nature of language learning, learning and communication strategies, and motivation and expectations are discussed separately in subsequent sections.

\subsection{Foreign language aptitude}

The category of foreign language aptitude considers the general existence of a special ability for language learning and beliefs about the characteristics of successful language learners. The students' beliefs in this category are less different for learning English and Arabic than the other three belief categories and as shown in Table 2, their mean scores are very close. The partial Eta Squared for this category (.013) is also the smallest among the four categories which turned out to be significant. While $80 \%$ of the students agreed that learning English is easier for children, fifty percent held the same belief about Arabic. Sixty-three percent believed that learning English is easier for someone who already speaks a foreign language, while fifty-six percent in the Arabic group agreed with this idea. Also, $40 \%$ in Arabic and 34\% in the English group endorsed the idea of women's superiority in language learning. These beliefs reflect the popular beliefs 
in Iranian society about learning English and Arabic. They might be influenced, further, by the current methodologies in teaching English and Arabic.

\subsection{The nature of language learning}

BALLI items in the category of the nature of language learning, concern issues related to the nature of language learning process. The students held the most different beliefs about learning English and Arabic in this category. The greatest partial Eta squared (.282) was seen in this category indicating that $28 \%$ of the variance in the students' beliefs is attributable to the target language. Forty percent of the students believed that in order to speak English it is necessary to know about English-speaking cultures, while only $13 \%$ of students in the Arabic group believed in the importance of Arabic-speaking cultures in learning Arabic. This point again stresses the popularity of western cultures in the social context especially for the young generation whereas Arab cultures lack this attractiveness. Another point might be that many students might not consider Arab culture and/or in the broad sense, Islamic culture, as very different from their own culture, and as a result of this cultural commonality, they don't feel it as a necessary requisite for learning Arabic. Seventy-three percent of the Arabic group agreed that the most important part of learning Arabic is learning the grammar, and sixty-two percent of the English group reported holding the same idea. This belief reflects the fact that in high-school Arabic classes, Arabic grammar is receiving great emphasis. The reason is that there's a considerable overlap between Arabic and Persian vocabulary, so the class time is mainly spent working on grammar. In English classes, however, students are more often concerned about the new vocabulary; hence there are a smaller number of students who believed in the importance of English grammar. Also, 58\% of the English and 53\% of the Arabic group believed that language learning involves a lot of memorization. These beliefs and the fact that they are supported by considerable numbers of the participants are probably reflecting the prevalence of grammar-translation method in their English and Arabic classes (Dolati \& Seliman, 2011).

\subsection{Learning and communication strategies}

Items in the category of learning and communication strategies refer to various strategies learners use to master a second or foreign language. About $90 \%$ of students in the English group agreed that it is important to speak English with an excellent pronunciation while $80 \%$ in the Arabic group believed in the importance of pronunciation in learning Arabic. Along the same line, $60 \%$ of students in the English group believed that it is important to practice with tapes or cassettes, while only $45 \%$ of the Arabic group agreed with that notion. These beliefs reflect the fact that in the educational system little importance is given to the oral skills in teaching and learning Arabic and that in reality there hardly exist such tapes or cassettes available for students to practice their Arabic at school and elsewhere, while this is not the case for English. From a pragmatic point of view, this lack of facilities for learning Arabic oral skills can be surprising: Many Iranians have the experience of travelling to Arabic-speaking countries such as Iraq, Syria or Saudi Arabia for visiting holy shrines or doing the Haj at least once in their lives, while many more of them never visit any English-speaking country. One might reasonably expect them to try learning Arabic oral skills more. Fifty percent of students in the Arabic and 57\% of them in the English group stated that if they don't know the meaning of the new words, it is ok to guess. In addition, the overwhelming majority (92\%) of the students in both groups believed that in learning languages it is important to repeat and practice a lot. These beliefs demonstrate that the students are aware of learning and communication strategies and use them in their own language learning processes. This is an especially positive point since they do not receive a strategy-based instruction at school.

\subsection{Motivation and expectations}

The last category, motivation and expectations, concerns the desire and expectation for language learning opportunities. This category had the next highest partial Eta Squared (.064) after the category of foreign language aptitude, emphasizing that the difference of students' motivation for learning English and Arabic was also outstanding among the four significant categories. Sixty-five percent of students in the English group agreed with the sentence "People in my country feel that it is important to speak English." Only 35\% agreed with the corresponding sentences in the Arabic group. Consistent with this result, $80 \%$ stated that if they learn English well, they would have better opportunities for a good job, while there was only $47 \%$ agreement with the corresponding sentences in the Arabic group. Also, when asked if they would like to learn English/Arabic very well, $89 \%$ in the English group and 70\% in the Arabic group had an affirmative answer. These beliefs show that high-school students are instrumentally motivated to learn English and that they are more strongly motivated to learn English than Arabic since English is the dominant foreign language both in occupational and academic contexts in Iran. The superior status of English as compared with Arabic is explained and elaborated in the introduction section.

\section{Conclusion and Pedagogical Implications}

The findings of the present study, the first one to compare high-school students' beliefs about learning different target languages, namely English and Arabic, revealed that high-school students held significantly different beliefs about learning these two foreign languages, many of which appears to be tied up with the socio-cultural status of the two foreign languages in Iranian context. In general, the students had more strongly expressed beliefs about learning English compared to Arabic. They reported more sophisticated and positive beliefs about the nature of learning English and about English learning aptitude than they did about learning Arabic. They also showed more positive attitudes toward English-speaking cultures. They reported using more learning and communication strategies in learning English and finally, they were more strongly motivated to learn English than Arabic. 
From a pedagogical point of view, the findings of this study are beneficial for teachers, curriculum developers and textbook designers in parallel ways. English and Arabic teachers can gain insights into their students' language learning beliefs. These insights can lead them to more effective instructional planning and implementation. They should try to modify misconceptions and erroneous beliefs that inhibit and restrict learning and foster positive beliefs that facilitate learning. They should take into account learners' beliefs in choosing their teaching methodologies. Since most students in this study hold strong beliefs about the importance of translation and grammar, teachers should draw their students' attention to the importance of oral skills in order to adapt a communicative approach in teaching and learning English language.

Foreign language educators and curriculum developers can also take these findings into account in making decisions about selecting identical or different language education policies in teaching foreign languages in Iran. One salient finding of this study is the students' lower level of motivation for learning Arabic compared to English. Considering the importance of Arabic language in conveying religious and cultural heritage, curriculum developers and textbook designers may take this finding into account and try to develop more effective teaching materials and methodologies in order to compensate for this lack of motivation and improve foreign language education in high school context.

\section{References}

Abedini, a., Rahimi, A., \& Zare-ee, A. (2011). Relationship between Iranian EFL learners' beliefs about language learning, their language learning strategy use and their language proficiency. Procedia Social and Behavioral Sciences 28, 1029 - 1033. http://dx.doi.org/10.1016/j.sbspro.2011.11.188

Altan, M.Z. (2006). Beliefs about language learning of foreign language-major university students. Australian Journal of Teacher Education 31, 45-52. http://dx.doi.org/10.14221/ajte.2006v31n2.5

Barcelos, A. M. F. (2000). Understanding teachers' and students' language learning beliefs in experience: a Deweyan approach. Unpublished doctoral dissertation. The University of Alabama, Tuscaloosa.

Bernat, E. \& Lloyd, R. (2007). Exploring the Gender Effect on EFL Learners' Beliefs about Language Learning. Australian Journal of Educational \& Developmental Psychology 7, 79-91.

Dehghan Harati, R. (2011). Learners' beliefs, teachers' beliefs: are they different? Iranian EFL Journal 7, 190-221.

Diab, R.L. (2006). University students' beliefs about learning English and French in Lebanon. System 34, 80-96.

http://dx.doi.org/10.1016/j.system.2005.06.014

Dolati, R. \& Seliman, S. (2011). An investigation of Iranian students' weaknesses in spoken English. Journal of Edupres 1, 94-99.

Ghabanchi, Z. \& Meidani, E. (2010). Beliefs about language learning and strategy use: the case of Iranian non-English majors. World Journal of English Language 2, 21-30.

Ghavamnia, M., Kassaian, Z. \& Dabaghi, A. (2011). The relationship between language learning strategies, language learning beliefs, motivation, and proficiency: A study of EFL learners in Iran. Journal of Language Teaching and Research 2, 1156-1161. http://dx.doi.org/10.4304/j1tr.2.5.1156-1161

Horwitz, E. K. (1999). Cultural and situational influences on foreign language learners' beliefs about language learning: A review of BALLI studies. System 27, 557-576. http://dx.doi.org/10.1016/S0346-251X(99)00050-0

Horwitz, E.K. (1987). Surveying student beliefs about language teaming. In A.L. Wenden \& J. Robin (Eds.), Learner strategies in language learning (pp. 119-132). London: Prentice Hall.

Khodadady, E. (2009). The beliefs about language learning inventory: factorial validity, formal education and the academic achievement of Iranian students majoring in English. Iranian Journal of Applied Linguistics 12,115- 166.

Oh, M. (1996). Beliefs about language learning and foreign language anxiety: A study of American university students learning Japanese. Unpublished Doctoral Dissertation, The University of Texas at Austin, Austin, TX.

Park, N. (2007). The influences of language anxiety on the use of learning strategies. The Linguistic Association of Korea Journal 15, 309-328.

Rieger, B. (2009). Hungarian university students` beliefs about language learning: a questionnaire study. WoPaLP 3 , 97-113.

Sakui, K. \& Gaies, S.J. (1999). Investigating Japanese learners' beliefs about language learning. [Special Issue]. System 27, 473-492. http://dx.doi.org/10.1016/S0346-251X(99)00046-9

Tercanlioglu, L. (2004). Exploring gender effect on adult foreign language learning strategies. Issues in Educational Research 14, 181-193.

Truitt, S.N. (1995). Anxiety and beliefs about language learning: a study of Korean university students learning English. Unpublished Doctoral Dissertation, The University of Texas at Austin, Austin, TX.

Victori, M., \& Lockhart, W. (1995). Enhancing metacognition in self-directed language learning. System 23, 223-234.

http://dx.doi.org/10.1016/0346-251X(95)00010-H 
Wenden, A. (1986). What do second language learners know about their language learning? A second look at retrospective accounts. Applied Linguistics 7, 186-205. http://dx.doi.org/10.1093/applin/7.2.186

Yamini, M. \& Dehghan, F. (2005). Relationship between foreign language beliefs, proficiency level and the use of language strategies (case study: Female English majors in Shiraz). Journal of Humanities 15, 123-149.

Yang, N. D. (1999). The relationship between EFL learners' beliefs and learning strategy use. System 27, $515-535$.

http://dx.doi.org/10.1016/S0346-251X(99)00048-2

Young, D.J., 1991. Creating a low-anxiety classroom environment: what does language anxiety research suggest? Modern Language Journal 75, 426-439. http://dx.doi.org/10.1111/j.1540-4781.1991.tb05378.x

Zare-ee, A. (2010). Associations between university students' beliefs and their learning strategy use. Procedia Social and Behavioral Sciences 5, 882-886. http://dx.doi.org/10.1016/j.sbspro.2010.07.203 